\title{
Crescimento de porta-enxertos de goiabeira influenciado por doses de biofertilizante, tipo e volume de substrato
}

\section{Growth of guava rootstocks influenced by biofertilizer doses, type and volume of substrate}

\author{
Marlon Breno Vieira de Sousa DINIZ ${ }^{1}$; Evandro Franklin de MESQUITA ${ }^{2}$; Francisco Vanies da Silva \\ SÁ $^{3}$; Emanoela Pereira de PAIVA ${ }^{4}$; José Flavio Vieira DINIZ ${ }^{1}$; Cesenildo de Figueiredo SUASSUNA ${ }^{1}$ \\ ${ }^{1}$ Graduados em Licenciatura Plena em Ciências Agrárias pela Univesidade Estadual da Paraíba. Email: \\ cesenildo@hotmail.com \\ ${ }^{2}$ D. Sc. Professor da Univesidade Estadual da Paraíba - UEPB; Unidade Acadêmica de Ciências Agrárias; Campus IV, \\ Catolé do Rocha-PB, Email: elmesquita4@uepb.edu.br \\ ${ }^{3}$ Autor para correspondência; Francisco Vanies da Silva Sá; Engenheiro Agrônomo, Mestrando em Manejo de Solo e \\ Água; Universidade Federal Rural do Semi-Árido - UFERSA, Departamento de Ciencias Ambientais e Tecnologicas; \\ Campus Mossoró, CEP.59.625-900, Mossoró-RN, Brasil. Email.: vanies_agronomia@hotmail.com; \\ ${ }^{4}$ Doutoranda em Fitotecnia; Universidade Federal Rural do Semi-Arido - UFERSA; Campus Mossoró, Email.: \\ emanuelappaiva@hotmail.com
}

Recebido em: 10-06-2014; Aceito em: 29-11-2014

\begin{abstract}
Resumo
Objetivou-se avaliar os efeitos do emprego de esterco bovino em associação com biofertilizante líquido, aplicado em dois tipos de solo, para produção de porta-enxerto de goiabeira. O delineamento experimental foi 0 inteiramente casualizado, em esquema fatorial $5 \times 2 \times 2$, sendo avaliados os fatores doses de biofertilizante $\left(0,0 ; 2,5 ; 5,0 ; 7,5\right.$ e 10,0\% v/v), 2 tipos de solos ( $S_{1}$ :Neossolo Flúvico e $S_{2}$ :Luvissolo Háplico) e 2 volumes de solo $(1 \mathrm{~L}$ e $2 \mathrm{~L}$ ), com três repetições, totalizando 60 unidades experimentais. O biofertilizante bovino foi aplicado ao solo depois de diluído em água, na proporção de 1:3 (v/v), 24 horas antes da semeadura, 25 dias após a emergência das plântulas e, posteriormente, em intervalo de 30 DAS.O maior crescimento e o acúmulo de matéria seca foram obtidos nos porta-enxertos cultivados em recipientes com capacidade para $2 \mathrm{~L}$. De maneira geral, doses de biofertilizante próximas a $5 \%$ do volume do substrato proporcionaram o maior desenvolvimento dos porta-enxertos de goiabeira. Os tipos de solo afetaram o crescimento dos porta-enxertos, sendo o Neossolo o mais promissor para produção de porta-enxertos de goiabeira.
\end{abstract}

Palavras-chave adicionais: adubação orgânica; propagação; Psidium guajava L.; recipientes.

\begin{abstract}
The objective of this study was to evaluate the effects of cow manure in association with biofertilizers applied to two soil types on the production of guava rootstock. The treatment replications were distributed according to a completely random design in a $5 \times 2 \times 2$ factorial arrangement with three replications. Five doses of biofertilizers $(0.0,2.5,5.0,7.5$, and $10.0 \% \mathrm{v} / \mathrm{v}), 2$ soil types (S1: Fluvisol and S2: HaplicLuvisol), and two volumes of soil $(1 \mathrm{~L}$ and $2 \mathrm{~L}$ ) were the combined factors. A total of 60 experimental units resulted from those combinations. Cow manure was applied to the soil after being diluted in water at the proportion of $1: 3(\mathrm{v} / \mathrm{v}) 24$ hours before sowing, 25 days after seedling emergence and, after that, at 30 day interval. The rootstocks showing the highest growth and dry matter accumulation were those growing in $2 \mathrm{~L}$ vases. In general, biofertilizer doses close to $5 \%$ of the substrate volume resulted in the largest rootstock growth. The Neossolo was the best soil for the production of guava rootstock.
\end{abstract}

Additional keywords: containers; organic fertilization; propagation; Psidium guajava L.

\section{Introdução}

$\mathrm{Na}$ fruticultura, existem várias espécies frutíferas de grande importância no Brasil; dentre estas, pode destacar-se a cultura da goiabeira, que tem a região Nordeste como a maior produtora (145.745 t) no ano de 2012, representada principalmente pelo Estado do Pernambuco (30,97\%) (IBGE, 2012). A goiaba (Psidium guajava L.) é uma das frutas tropicais mais populares e de boa aceitação no País em virtude de seu alto valor nutritivo, do alto rendimento cultural, da ampliação da atividade industrial e do potencial para exportação (Rozane \& Couto, 2003).

As goiabeiras são plantas nativas da América tropical e, no Brasil, encontram-se distribuídas por todo o território nacional (Ruggiero, 2009). Atualmente, seu cultivo é muito importante sob o ponto de vista econômico e social, para os estados brasileiros, principalmente na região Nordeste do Brasil. Dentre as cultivares mais plantadas, destaca-se a cultivar 
Paluma, por apresentar características excepcionais para o processamento industrial e o consumo in natura, além de sua produtividade e vigor (Pereira et al., 2003).

A produção de mudas é uma das fases mais importantes da condução do pomar, visto que mudas mais vigorosas influenciam diretamente na produtividade da cultura (Trindade et al., 2000). No entanto, a qualidade da muda depende de inúmeros fatores, como clima, potencial genético do porta-enxerto, substratos, irrigação e cuidados fitossanitários.

Para Zietemann \& Roberto (2007), o substrato destina-se a sustentar as plantas durante o enraizamento e servir de fonte de nutrientes para as plantas, além de fornecer aeração adequada e capacidade de retenção de líquido satisfatória para oferecer umidade adequada à muda. Os autores sugerem substratos, como utilizando mistura de solo (Latossolo) + matéria orgânica (esterco de curral) + areia fina (2:1:1), Plantmax® e fibra de coco Sococoß. No entanto, a Lei no 10.711, de 05-08-2003, regulamenta a produção de mudas e deve-se evitar a produção de mudas desta espécie com o uso de solos, devido à grande incidência de nematoides, limitando o uso de solos como componentes das misturas de substratos para produção de mudas de goiabeira.

Entretanto, é indispensável o desenvolvimento de substratos que atendam às exigências nutricionais das plantas e deem suporte físico ideal às plantas, que pode ocorrer mediante a substituição dos fertilizantes químicos de origem sintética do sistema convencional, por biofertilizantes líquidos associados com outros adubos orgânicos. Haja vista que testes realizados in vivo comprovaram que o biofertilizante líquido é um excelente nematicida e larvicida, agindo de maneira fumigante e asfixiante quando em contato com nematoides e larvas existentes em solos muito contaminados (Vairo \& Akiba, 1996).

Para Malavolta (1989), o biofertilizante é um composto biológico completo de nutrientes essenciais, que pode ser disponibilizado para as plantas, aplicado no solo, na irrigação ou por via foliar, possibilitando a obtenção de boas produções e a obtenção de frutos com adequada qualidade comercial e sanitária. Alguns estudos têm demonstrado que o uso de biofertilizantes na formulação do substrato pode atenuar as possíveis deficiências nutricionais e favorecer o crescimento das plantas na fase de produção de mudas (Sá et al., 2013; Dantas et al.,2014).

O volume do recipiente e o tipo de substrato são os primeiros aspectos que devem ser investigados para garantir a produção de porta-enxerto de excelente qualidade. $\mathrm{O}$ volume do recipiente deve ser tal que permita o desenvolvimento do sistema radicular sem restrições significativas, durante 0 período de permanência no viveiro. Da mesma forma, o substrato exerce influência marcante na arquitetura do sistema radicular e no estado nutricional das plantas, afetando profundamente a qualidade das mudas (Carneiro, 1983). Portanto, esses fatores são de fundamental importância para obtenção de mudas de excelente qualidade.

Os solos Neossolos e Luvissolos são os de maiores ocorrências em regiões semiáridas do Nordeste brasileiro, justificando a presente pesquisa. Assim, objetivou-se, com este trabalho, avaliar os efeitos do emprego de esterco bovino em associação com biofertilizante líquido, aplicados em dois tipos de solo para produção de porta-enxerto de goiabeira.

\section{Material e métodos}

O experimento foi conduzido no município de Catolé do Rocha, Paraíba $\left(6^{\circ} 2^{\prime} 38^{\prime \prime}\right.$ de latitude sul, $37^{\circ} 44^{\prime} 48^{\prime \prime}$ de longitude oeste e altitude de $275 \mathrm{~m}$ ). $\mathrm{O}$ viveiro foi cercado e coberto com tela permitindo $50 \%$ de luminosidade e boa ventilação em seu interior.

Para o preparo do substrato, utilizou-se de amostras de dois solos, sendo um Neossolo Flúvico eutrófico e Luvissolo Háplico eutrófico, solos predominantes na região Nordeste, principalmente no Estado da Paraíba (Santos et al., 2006). Após coletadas as amostras de solo na camada superficial dos solos $(0-20 \mathrm{~cm})$, estas foram colocadas para secar ao ar, destorroadas e peneiradas com peneira com malha de $2 \mathrm{~mm}$, segundo metodologia proposta pela EMBRAPA (2006). Foi realizada a caracterização físico-químicas da mesma no Laboratório de Irrigação e Salinidade (LIS) do Centro de Tecnologia e Recursos Naturais da Universidade Federal de Campina Grande (UFCG) (Tabela 1). Ainda para o preparo do substrato, foram utilizadas amostras de esterco bovino curtido, o qual também passou pelos mesmos procedimentos de secagem, sendo destorroado e peneirado em peneira com malha de $2 \mathrm{~mm}$ e caracterizado quimicamente no Laboratório de Irrigação e Salinidade (LIS) do Centro de Tecnologia e Recursos Naturais da Universidade Federal de Campina Grande (UFCG), seguindo metodologia proposta pela EMBRAPA (2006) (Tabela 2).

Após a caracterização físico-química dos componentes do substrato (solo e esterco), foi realizada a mistura dos mesmos na proporção de 1:1, $50 \%$ de solo e $50 \%$ de esterco bovino, os quais foram acondicionados em sacos de polietileno apropriados para produção de mudas, com capacidade para comportar 1 e $2 \mathrm{~L}$ do substrato, conforme os tratamentos propostos.

O biofertilizante enriquecido com leguminosa e pó de pedra, à base de esterco bovino, foi produzido, de forma anaeróbia, em recipiente plástico, com capacidade para 240 L, contendo uma mangueira ligada a uma garrafa de plástico transparente com água para a retirada do gás metano, produzido no interior do recipiente, pela fermentação das bactérias anaeróbias. O material utilizado para a produção do referido fertilizante constou de $70 \mathrm{~kg}$ de esterco verde de vacas em lactação e de $120 \mathrm{~L}$ de água, além de $5 \mathrm{~kg}$ de açúcar e $5 \mathrm{~L}$ de leite para aceleração do metabolismo das bactérias, mais $5 \mathrm{~kg}$ de matéria verde de leguminosa (feijão) e 
4 kg de pó de pedra (Tabela 3), o qual permaneceu sob condições de fermentação anaeróbia constante, durante 60 dias, garantindo a decomposição do insumo. Após o preparo, foram coletadas amostras do biofertilizante e encaminhadas para o Laboratório de Irrigação e Salinidade (LIS) do Centro de Tec- nologia e Recursos Naturais da Universidade Federal de Campina Grande (UFCG), no qual se realizou a caracterização química da matéria seca do mesmo, seguindo metodologia proposta pela EMBRAPA (2006) (Tabela 3).

Tabela 1 - Características físicas e químicas do solo1 (Neossolo Flúvico) e do solo 2 (Luvissolos Háplicos), utilizados no experimento. Physical and chemical characteristics of soil 1 (Entisol) and soil 2 (Haplic Luvisols), used in the experiment.

\begin{tabular}{|c|c|c|c|}
\hline \multirow{2}{*}{\multicolumn{2}{|c|}{ Características Físicas }} & \multicolumn{2}{|c|}{ Valor } \\
\hline & & Neossolo & Luvissolo \\
\hline \multirow{3}{*}{ Granulometria } & Areia $\left(\mathrm{g} \mathrm{kg}^{-1}\right)$ & 640,00 & 524,90 \\
\hline & Silte $\left(\mathrm{g} \mathrm{kg}^{-1}\right)$ & 206,00 & 423,60 \\
\hline & Argila $\left(\mathrm{g} \mathrm{kg}^{-1}\right)$ & 154,00 & 51,50 \\
\hline \multicolumn{2}{|c|}{ Classificação textural } & Franco Arenoso & Franco Siltoso \\
\hline \multicolumn{2}{|c|}{ Densidade global $\left(\mathrm{g} \mathrm{dm}^{-3}\right)$} & 1,54 & 1,28 \\
\hline \multicolumn{2}{|c|}{ Densidade das partículas $\left(\mathrm{g} \mathrm{dm}^{-3}\right)$} & 2,68 & 2,67 \\
\hline \multicolumn{2}{|c|}{ Porosidade total (\%) } & 42,54 & 52,16 \\
\hline \multicolumn{2}{|c|}{ Capacidade de campo $\left(\mathrm{g} \mathrm{kg}^{-1}\right)$} & 146,9 & 228,4 \\
\hline \multicolumn{2}{|c|}{ Ponto de murcha permanente $\left(\mathrm{g} \mathrm{kg}^{-1}\right)$} & 76,60 & 112,2 \\
\hline \multicolumn{2}{|c|}{ Água disponível $\left(\mathrm{g} \mathrm{kg}^{-1}\right)$} & 70,3 & 116,2 \\
\hline \multicolumn{4}{|c|}{ Características Químicas (Fertilidade) } \\
\hline \multicolumn{2}{|c|}{ Cálcio $\left(\mathrm{cmol}_{\mathrm{c}} \mathrm{dm}^{-3}\right)$} & 2,34 & 3,66 \\
\hline \multicolumn{2}{|c|}{ Magnésio $\left(\mathrm{cmol}_{\mathrm{C}} \mathrm{dm}^{-3}\right)$} & 2,41 & 2,33 \\
\hline \multicolumn{2}{|c|}{ Sódio $\left(\mathrm{cmol}_{\mathrm{c}} \mathrm{dm}^{-3}\right)$} & 0,02 & 0,06 \\
\hline \multicolumn{2}{|c|}{ Potássio $\left(\mathrm{cmol}_{\mathrm{c}} \mathrm{dm}^{-3}\right)$} & 0,33 & 0,72 \\
\hline \multicolumn{2}{|c|}{ Soma de bases $(\mathrm{S})\left(\mathrm{cmol}_{\mathrm{C}} \mathrm{dm}^{-3}\right)$} & 5,10 & 6,77 \\
\hline \multicolumn{2}{|c|}{ Hidrogênio $\left(\mathrm{cmol}_{\mathrm{c}} \mathrm{dm}^{-3}\right)$} & 0,69 & 0,06 \\
\hline \multicolumn{2}{|c|}{ Alumínio $\left(\mathrm{cmol}_{\mathrm{c}} \mathrm{dm}^{-3}\right)$} & 0,00 & 0,00 \\
\hline \multicolumn{2}{|c|}{ Capacidade de troca de cátions Total $\left(\mathrm{cmol}_{\mathrm{c}} \mathrm{dm}^{-3}\right)$} & 5,79 & 6,83 \\
\hline \multicolumn{2}{|c|}{ Saturação por Bases (V \%) } & 88,00 & 99,12 \\
\hline \multicolumn{2}{|c|}{ Carbonato de cálcio qualitativo } & Ausente & Ausente \\
\hline \multicolumn{2}{|c|}{ Carbono orgânico (\%) } & 0,47 & 0,31 \\
\hline \multicolumn{2}{|c|}{ Matéria orgânica (\%) } & 0,81 & 0,53 \\
\hline \multicolumn{2}{|c|}{ Nitrogênio (\%) } & 0,04 & 0,03 \\
\hline \multicolumn{2}{|c|}{ Fósforo assimilável ( $\left.\mathrm{mg} \mathrm{dm}^{-3}\right)$} & 18,30 & 21,90 \\
\hline \multicolumn{2}{|l|}{$\mathrm{pH} \mathrm{H} \mathrm{H}_{2} \mathrm{O}(1: 2,5)$} & 6,00 & 6,62 \\
\hline
\end{tabular}

Análises realizadas no Laboratório de Irrigação e Salinidade (LIS/DEAg/CTRN/UFCG), Campina Grande-PB.

Tabela 2. Características químicas do esterco bovino, utilizado no experimento. Chemical characteristics of bovine manure used in the experiment.

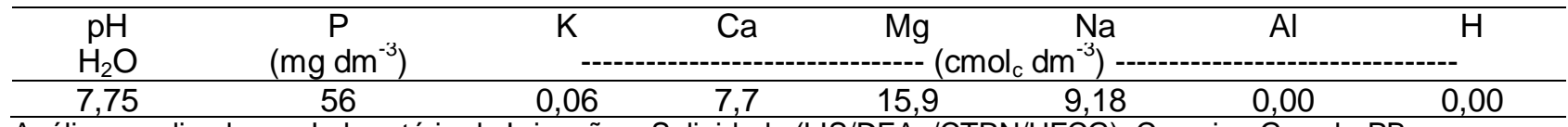

Análises realizadas no Laboratório de Irrigação e Salinidade (LIS/DEAg/CTRN/UFCG), Campina Grande-PB.

Tabela 3 - Composição química na matéria seca do biofertilizante à base de esterco, aos 60 dias após o início da fermentação anaeróbia. Chemical composition on dry matter basis of the biofertilizer bovine manure at 60 days after initiation of anaerobic fermentation.

\begin{tabular}{|c|c|c|c|c|c|c|c|c|}
\hline $\mathrm{pH}$ & $\begin{array}{c}\mathrm{CE}_{25^{\circ} \mathrm{C}} \\
\left(\mathrm{dS} \mathrm{m^{-1 }}\right)\end{array}$ & $\mathrm{Ca}^{+2}$ & $\mathrm{Mg}^{+2}$ & $\mathrm{Na}^{+1}$ & $\begin{array}{l}\mathrm{K}^{+1} \mathrm{Cl}^{-1} \\
\left(\mathrm{cmol}_{\mathrm{C}} \mathrm{L}^{-1}\right)\end{array}$ & $\mathrm{CO}_{3}{ }^{2-}$ & $\mathrm{HCO}_{3}^{-}$ & $\mathrm{SO}_{4}{ }^{2-}$ \\
\hline 6,34 & 8,08 & 3,71 & 2,40 & 3,27 & 1,69 & 0,43 & 2,03 & 1,02 \\
\hline
\end{tabular}

CE - condutividade elétrica do extrato de saturação. Análises realizadas no Laboratório de Irrigação e Salinidade (LIS/DEAg/CTRN/UFCG), Campina Grande-PB. 
Como a água da região Semiárida apresenta certa salinidade, a água utilizada na irrigação foi analisada no Laboratório de Irrigação e Salinidade (LIS) do Centro de Tecnologia e Recursos Naturais da Universidade Federal de Campina Grande (UFCG) e apresentou condutividade elétrica de $0,8 \mathrm{dS} \mathrm{m}^{-1}$, sendo considerada apropriada para a irrigação da goiabeira (Cavalcante et al., 2010). As características químicas da água estão apresentadas na Tabela 4.

A irrigação foi realizada com um volume uniforme de água às plantas, em função da evapotranspiração média no tratamento-testemunha, obtida por pesagem. O volume aplicado (Va) por recipiente foi obtido pela diferença entre a média do peso dos recipientes em condição de máxima retenção de água $\left(P_{c c}\right)$, o qual será determinado saturando-se os recipientes com água e submetendo-os à drenagem; quando o volume drenado estiver reduzindo, os recipientes serão pesados, obtendo-se o valor do $P_{c c}$ quando o peso dos recipientes com substrato for constante, e o peso médio dos recipientes na condição atual $\left(P_{a}\right)$, dividido pelo número de recipientes $(\mathrm{n})$, como indicado na equação 1 :

$\mathrm{Va}=\frac{P_{c c} \times P_{a}}{\mathrm{n}}$

Tabela 4 - Características químicas da água utilizada para irrigação. Chemical characteristics of the water used for irrigation.

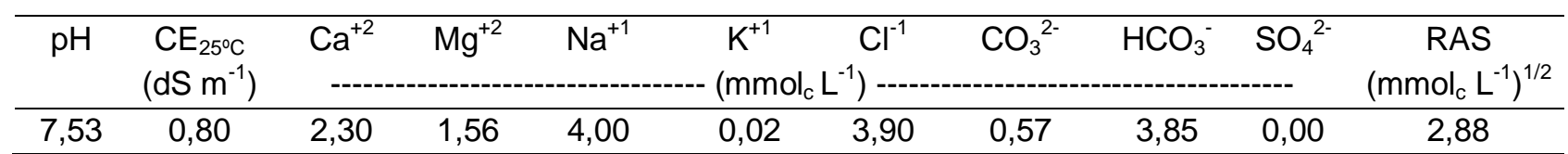

Análises realizadas no Laboratório de Irrigação e Salinidade (LIS/DEAg/CTRN/UFCG), Campina Grande-PB.

O delineamento experimental foi o inteiramente casualizado, em esquema fatorial 5 doses de biofertilizante $(0,0 ; 2,5 ; 5,0 ; 7,5$ e $10,0 \% \mathrm{v} / \mathrm{v}) \times 2$ tipos de solos $\left(\mathrm{S}_{1}\right.$ : Neossolo Flúvico e $\mathrm{S}_{2}$ : Luvissolo Háplico) $\times 2$ volumes de solo ( $1 \mathrm{~L}$ e $2 \mathrm{~L}$ ), com três repetições, totalizando 60 unidades experimentais.

O biofertilizante bovino foi aplicado ao solo depois de diluído em água, na proporção de $1: 3(\mathrm{~m} / \mathrm{v}), 24$ horas antes da semeadura e 25 dias após a emergência das plântulas, e, posteriormente, em intervalo de 30 dias, até 21 de janeiro de 2011, de acordo com o volume proposto no tratamento.

Após a incorporação do biofertilizante, os recipientes foram irrigados até que o solo atingisse a capacidade de campo (CC), de forma a garantir a efetivação do processo de germinação e de desenvolvimento das plântulas, realizando-se em seguida a semeadura com 7 sementes, de forma equidistante por vaso, a uma profundidade de $2,0 \mathrm{~cm}$. As sementes de goiaba, de frutos com polpa vermelha da variedade Paluma, foram coletadas de plantas-matrizes localizadas na microrregião de Catolé do Rocha-PB. Após a germinação, por volta dos vinte e cinco dias após a semeadura (25 DAS), foi realizado o desbaste, deixando-se apenas uma planta por recipiente, permanecendo assim até o final do experimento. Realizou-se ao longo do experimento o manejo fitossanitário, a fim de manter sob controle as populações de pragas e patógenos.

Aos 141 DAS, final do experimento, foram avaliados: a) Altura da planta (AP; $\mathrm{cm}$ ): obtida do colo à base da folha mais jovem com régua graduada em centímetro; b) Número de folhas (NF): foram consideradas apenas as que apresentavam comprimento mínimo de 2,0 cm; c) Diâmetro do caule (DC; $\mathrm{mm}$ ): foi determinado com um paquímetro, com as leituras sendo efetuadas a $2 \mathrm{~cm}$ de altura, na região do colo de cada planta, nos mesmos períodos estabelecidos para a mensuração da altura de plantas e da contagem do número de folhas; d) Área foliar (AF; $\mathrm{cm}^{2}$ ); foi calculada da seguinte forma: comprimento da folha $(C ; \mathrm{cm}) \times$ largura da folha $(\mathrm{L} ; \mathrm{cm}) \times$ fator de correção ( $f=0,8)$; e) Razão de área foliar (RAF): a partir dos dados de área foliar $\left(\mathrm{cm}^{2}\right)$ e matéria seca da parte aérea $(\mathrm{g})$, obtidos no final do experimento, determinou-se a RAF $\left(\mathrm{cm}^{2} \mathrm{~g}^{-1}\right)$, através da relação entre a AF e a fitomassa seca da parte aérea (FSPA; g), de acordo com a equação descrita por Ferri (1985).

$\mathrm{RAF}=\frac{\mathrm{AF}}{\mathrm{FSPA}}$

O material vegetal colhido foi separado em raízes, caules e folhas, que foram secos em estufa de circulação de ar à temperatura de $60^{\circ} \mathrm{C}$, até atingirem massa constante. A obtenção da matéria seca total (MST) deu-se através da soma das massas secas de cada uma dessas partes. A relação raíz/parte aérea foi calculada pelo coeficiente entre os valores de fitomassa seca das raízes e os de fitomassa seca da parte aérea da planta, obtidos no final do experimento.

Os dados foram submetidos à análise de variância, ao nível de significância de $5 \%$. Com base na significância dos dados, procedeu-se à análise de regressão para os dados quantitativos, e o teste de Tukey, a $5 \%$ de probabilidade, para os fatores qualitativos, utilizando o aplicativo SISVAR (Ferreira, 2011).

\section{Resultados e discussão}

Foi observado efeito significativo da interação tipo de solo, volume de solo e dose de biofertilizante para AT, DC, RAF para AF (Tabela 5). Consta ainda 
na mesma tabela que, para NF, foi verificado apenas efeito significativo da interação tipo de solo e volume do solo, e efeito isolado da dose de biofertilizante. Os resultados obtidos concordam com Dantas et al.
(2014), que observaram efeito significativo de doses de biofertilizante e substratos (com $25 \%$ e $50 \%$ de esterco bovino) sob o crescimento de mudas de aceroleira.

Tabela 5 - Resumo das análises de variância referente às variáveis altura da planta (AP), diâmetro caulinar (DC), número de folhas (NF), área foliar (AF) e razão da área foliar (RAF) em porta-enxerto de goiabeira. Summary of the analyses of variance for plant height (AP), stem diameter (DC), leaf number (NF), leaf area $(\mathrm{AF})$, in guava rootstocks.

\begin{tabular}{|c|c|c|c|c|c|c|}
\hline \multirow{2}{*}{$\begin{array}{l}\text { Fonte de } \\
\text { Variação }\end{array}$} & \multicolumn{6}{|c|}{ Quadrado Médio } \\
\hline & $\mathrm{GL}$ & $\mathrm{AP}$ & $\mathrm{DC}$ & NF & $\mathrm{AF}$ & RAF \\
\hline Repetição & 2 & $43,52^{\text {ns }}$ & $0,14^{\mathrm{ns}}$ & $20,85^{\mathrm{ns}}$ & $2688^{\text {ns }}$ & $8618^{\text {ns }}$ \\
\hline Biofertilizante (B) & 4 & $419,91^{* *}$ & $4,49^{\star \star}$ & $40,90^{\star *}$ & $60964^{\star *}$ & $15686^{\star \star}$ \\
\hline Tipos de solo (S) & 1 & $1,83^{\mathrm{ns}}$ & $0,12^{\mathrm{ns}}$ & $28,01^{\mathrm{ns}}$ & $1464^{\mathrm{ns}}$ & $39^{\mathrm{ns}}$ \\
\hline Volume de solo (V) & 1 & $451,00^{\star *}$ & $3,15^{\star}$ & $74,81^{\star *}$ & $3299^{\text {ns }}$ & $427^{\mathrm{ns}}$ \\
\hline Interação B*S & 4 & $262,75^{\star \star}$ & $0,82^{* *}$ & $11,93^{\mathrm{ns}}$ & $9254^{*}$ & $346^{\mathrm{ns}}$ \\
\hline Interação B*V & 4 & $134,75^{\star \star}$ & $0,84^{\star \star}$ & $9,73^{\mathrm{ns}}$ & $11528^{\star \star}$ & $8036^{\star \star}$ \\
\hline Interação S*V & 1 & $119,00^{*}$ & $0,11^{\mathrm{ns}}$ & $30,81^{*}$ & $2543^{\mathrm{ns}}$ & $2056^{\mathrm{ns}}$ \\
\hline Interação NB* ${ }^{*} V$ & 4 & $118,29^{* *}$ & $1,33^{* *}$ & $11,40^{\mathrm{ns}}$ & $8074,71^{*}$ & $5300^{\star *}$ \\
\hline Resíduo & 38 & 20,04 & 0,05 & 7,09 & 2797,56 & 591 \\
\hline CV (\%) & & 14,75 & 6,73 & 14,36 & 18,99 & 24,79 \\
\hline
\end{tabular}

GL - Grau de Liberdade; CV - Coeficiente de Variação; ns - Não Significativo; ${ }^{* \star}=$ ao nível de $1 \%$ de probabilidade; ${ }^{*}=$ ao nível de $5 \%$ de probabilidade.

Para altura do porta-enxerto de goiabeira, observou-se resposta quadrática em função das doses do biofertilizante, em ambos os solos e volumes avaliados (Figura 1). Nas plantas cultivadas no Neossolo, as melhores respostas deram-se nas doses de 4,5 e $4,1 \%$ no substrato, referente aos volumes de solo de 1 e $2 \mathrm{~L}$, correspondendo à altura de 34,06 e $39,35 \mathrm{~cm}$, respectivamente (Figura 1). Para o cultivo no Luvissolo (S2), os maiores valores em altura foram de 36,98 e $38,15 \mathrm{~cm}$, sendo obtidos com as doses estimadas de biofertilizantes de 7,2 e $5,0 \%$, correspondentes aos volumes de solo de 1 e $2 \mathrm{~L}$, respectivamente (Figura 1). Constata-se que as plantas cultivadas no Luvissolo necessitaram de quantidades maiores de biofertilizantes para atingir o pico máximo de altura, possivelmente em função do maior teor de silte e de menores teores de argilas presentes nesse solo, limitando a adsorção de nutrientes no mesmo e, com isso, restringindo a disponibilidade deles às plantas (Tabela 1). Observase ainda que as maiores alturas foram obtidas nos porta-enxertos de goiabeira cultivados em recipientes com capacidade para dois litros de substrato, independentemente do tipo de solo utilizado (Figura 1).

A partir das doses de biofertilizante estimadas de 7,2 e 5,0\% correspondentes aos volumes 1 e $2 \mathrm{~L}$, respectivamente, houve efeito depressivo no crescimento em altura dos porta-enxertos, o que pode ser caracterizado como super dose de biofertilizantes, quando associado aos nutrientes provenientes do solo e do esterco bovino, ocasionando possíveis desordens nutricionais, reerigindo com isso o crescimento dos porta-enxertos com o aumento das doses de biofertilizante. Os resultados obtidos na pesquisa com 0 uso de biofertilizante são semelhantes aos observados por Zietemann \& Roberto (2007), utilizando mistura de solo (Latossolo) + matéria orgânica (esterco de curral) + areia fina (2:1:1), Plantmax ${ }^{\circledR}$ e fibra de coco Sococo $\AA$.

O crescimento em diâmetro caulinar respondeu significativamente à interação doses de biofertilizante $x$ tipos de solos $x$ volumes (Tabela 5). Verificou-se para os tratamentos contendo Neossolo, em recipientes com $1 \mathrm{~L}$, que os porta-enxertos responderam de forma quadrática à adubação com biofertilizante, atingindo o máximo de diâmetro caulinar $(4,31 \mathrm{~mm})$ na dose de $5,06 \%$ do volume do substrato. Nos recipientes com $2 \mathrm{~L}$ contendo Neossolo, não foi verificado influência das doses de biofertilizante sob o crescimento em diâmetro do caule, averiguando a média de $3,82 \mathrm{~mm}$ por porta-enxerto (Figura 2). Para os tratamentos com Luvissolos (S2), os diâmetros aumentaram até as doses de biofertilizantes estimadas de 6,66 e $4,54 \%$, atingindo os diâmetros máximos de 3,96 e 4,76 mm para os volumes de 1 e $2 \mathrm{~L}$, respectivamente (Figura 2).

Verifica-se que as plantas cultivadas no Neossolo, em recipientes de $1 \mathrm{~L}$, atingiram diâmetros superiores aos cultivados no Luvissolo sob os mesmos recipientes, exigindo doses menores de biofertilizante, indagando seu melhor desempenho para produção de porta-enxertos de goiabeira, possivelmente em função de seu maior teor de argila e areia, proporcionando maior número de cargas negativas e melhor aeração das raízes dos porta-enxertos, favorecendo o maior crescimento dos mesmos (Tabela 1). 

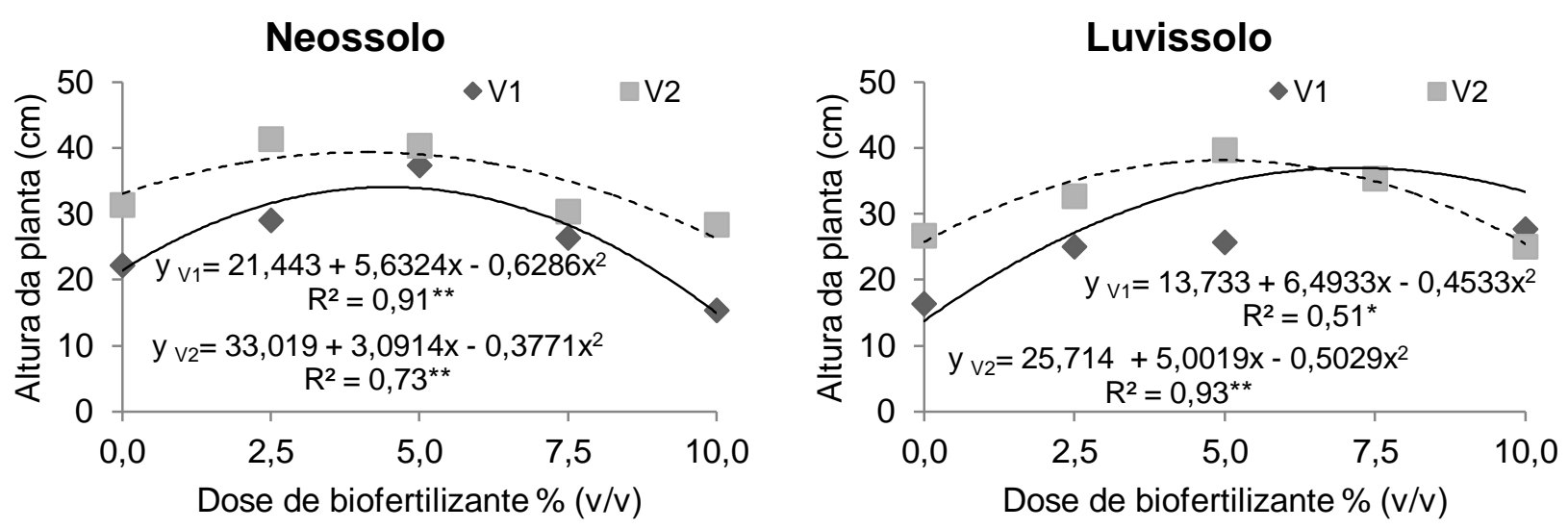

Figura 1 - Altura de porta-enxertos de goiabeira em função da dose de biofertilizante, volume e tipo do solo usado como substrato. V1 = $1 \mathrm{~L} ; \mathrm{V} 2=2 \mathrm{~L}$. Guava rootstocks height as influenced by dose of biofertilizer, volume and type of soil used as substrate.

Acredita-se que, neste substrato, além da presença favorável do esterco bovino e dos solos Neossolo e Luvissolo, foi importante a utilização do biofertilizante bovino, já que este componente tem a capacidade de alterar beneficamente as propriedades físicas, químicas e biológicas do solo. Ainda, pode melhorar a capacidade de retenção de água, por ser matéria orgânica, além de possuir em sua

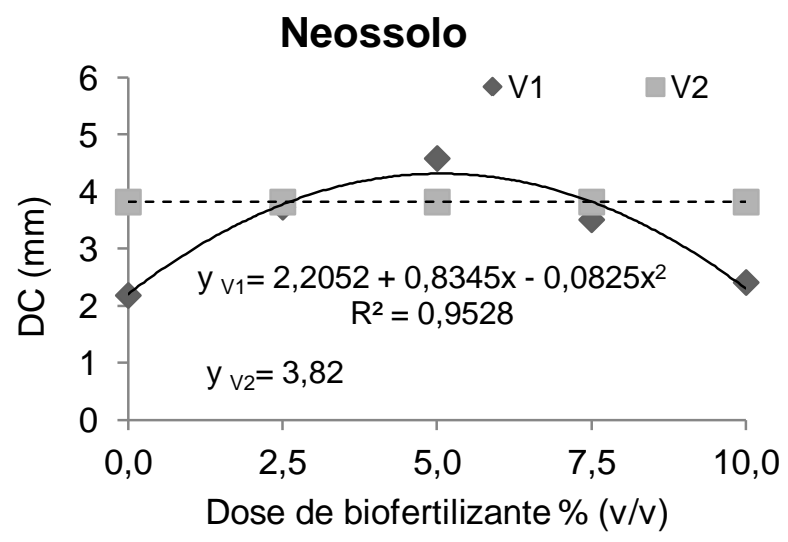

composição nutrientes essenciais ao crescimento e desenvolvimento das plantas. Respostas positivas do crescimento em diâmetro caulinar também foram verificadas por Cavalcante et al. (2010), trabalhando com a cultivar Paluma. Os autores observaram que 0 diâmetro das plantas submetidas à aplicação de biofertilizante e águas salinas teve incremento de 72,41 \% em relação às que não receberam o insumo.

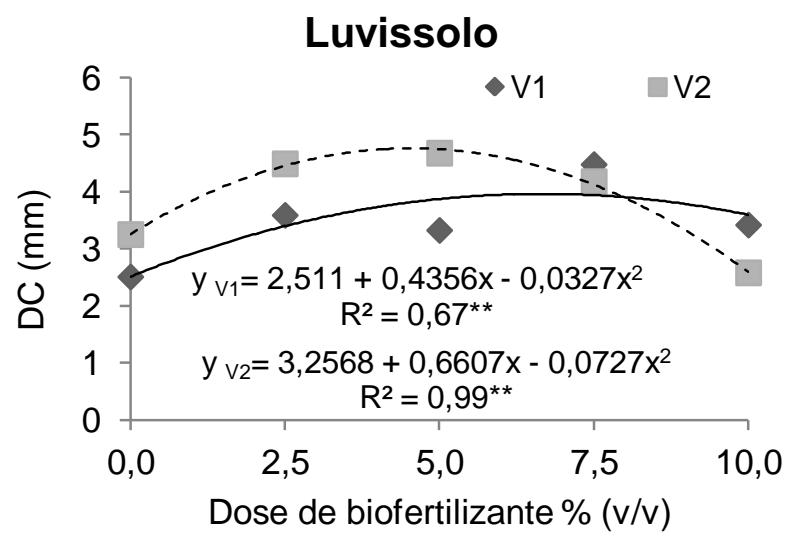

Figura 2 - Diâmetro do caule (DC) de porta-enxertos de goiabeira em função da dose do biofertilizante, volume e tipo do solo usado como substrato. V1 = $1 \mathrm{~L} ; \mathrm{V} 2=2 \mathrm{~L}$. Guava rootstocks stem diameter (DC) as influenced by dose of biofertilizer, volume and type of soil used as substrate.

Quanto ao número de folhas, verificou-se efeito significativo da interação entre os solos e os volumes aplicados na produção de goiabeira, observando que os porta-enxertos cultivados em substrato contendo Neossolo obtiveram número de folhas $15,32 \%$ maior em relação aos cultivados no substrato com Luvissolo, quando cultivados em recipientes de $2 \mathrm{~L}$ (Figura $3 \mathrm{~A}$ ). Tais resultados deram-se em função da textura arenoargilosa observada no Neossolo, favorecendo a maior retenção de nutrientes e aeração do substrato, e que as características siltosas do Luvissolo ao ser associado ao esterco podem ter favorecido o estresse hipóxico nos porta-enxertos de goiabeira devido à maior capacidade de retenção de água no substrato, prejudicando 0 crescimento dos porta-enxertos
(Tabela 1). No entanto, quando cultivados nos recipientes de $1 \mathrm{~L}$, não foi contatada diferença entre os solos utilizados, possivelmente em função da maior expressão do teor de esterco bovino adicionado na confecção dos substratos (Figura 3A).

Constatou-se resposta quadrática do número de folhas dos porta-enxertos de goiabeira em função das doses de biofertilizante, que obtiveram maior número de folhas $(20,45$ folhas por planta) quando adubados com $4,9 \%$ do volume do recipiente (Figura 3B). A partir dessa dose, ocorreram decréscimos significativos no número de folhas por planta, talvez em razão de essas doses contribuírem para o aumento do teor de nutrientes no substrato, possivelmente ocasionando desordens nutricionais sob as plantas de goiabeira. Os resultados observados 
foram superiores às 16 folhas observadas por Gurgel et al. (2007), trabalhando com as cultivares Rica e Ogawa irrigadas com água a $0,5 \mathrm{dS} \mathrm{m}^{-1}$, e substrato composto por mistura de casca de arroz carbonizada,

A

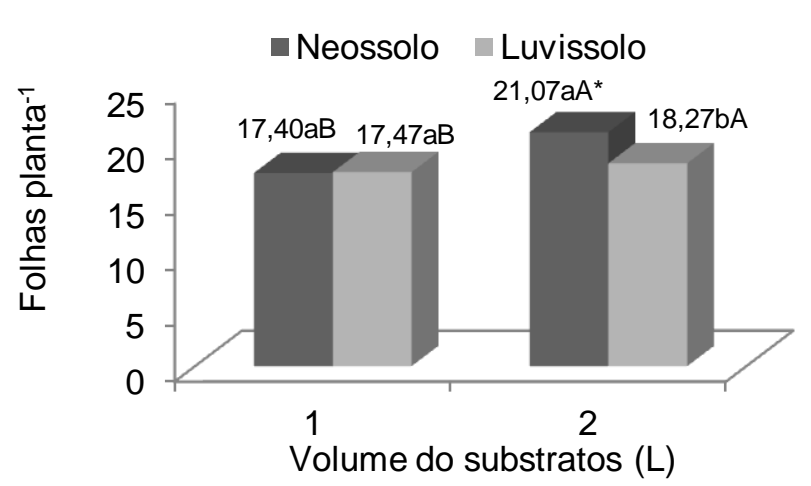

palha de carnaúba triturada e húmus (proporção de $2: 1: 1$. Denota-se com isso que a aplicação do biofertilizante em doses adequadas viabiliza a produção de porta-enxertos de goiabeira Paluma.

B

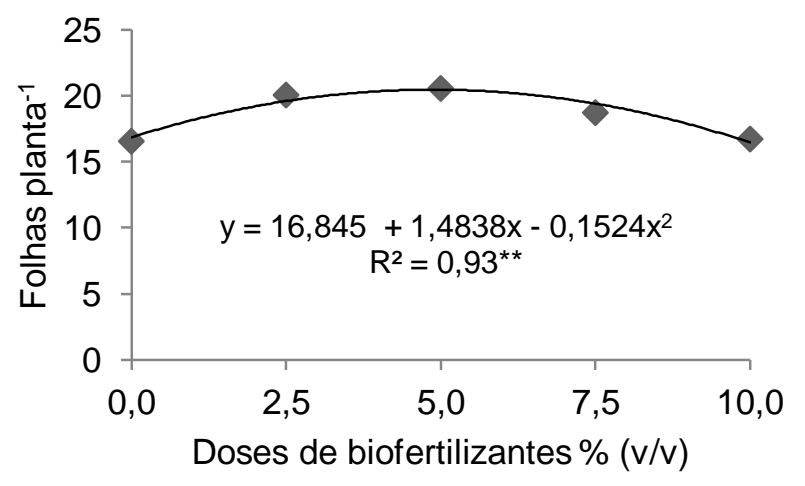

Figura 3 - Número de folhas do porta-enxerto de goiabeira em função de doses de biofertilizante, volume e tipo do solo usado como substrato. ${ }^{*}$ Letras iguais maiúsculas não diferem quanto ao desempenho no tipo de solo, e iguais minúsculas não diferem quanto ao desempenho no volume do recipiente quanto ao teste de Tukey, a $5 \%$ de probabilidade. Guava rootstocks number of leaves as influenced by dose of biofertilizer, volume and type of soil used as substrate. *Values followed by the same uppercase letter indicate similar performance in the two types of soil whereas values followed by the same lowercase letter indicate similar performance in both soil volumes.

Foram constatadas respostas quadráticas da área foliar dos porta-enxertos de goiabeira em função das doses de biofertilizante em ambos os tipos de solo e de volumes do recipiente. Observa-se que as doses ótimas para o cultivo no Neossolo foram de 4,88 e $3,52 \%$ do volume para os recipientes de 1 e $2 \mathrm{~L}$, com áreas foliares correspondentes de 396 e $327 \mathrm{~cm}^{2}$, respectivamente. No substrato com Luvissolo (S2), acondicionados em sacos de polietileno com capacidade para 1 e $2 \mathrm{~L}$, observaram-se as áreas máximas estimadas de 354 e $352 \mathrm{~cm}^{2}$ quando foram aplicadas as doses de 5,34 e $3,81 \%$ do volume do substrato, respectivamente (Figura 4). Pode-se constatar que a maior área foliar foi observada nos porta-enxertos cultivados em substrato com Neossolo, em recipientes com $1 \mathrm{~L}$, em relação aos demais tratamentos que não diferiram entre si, em relação às máximas áreas foliares estimadas. Acredita-se que estes resultados estejam relacionados à maior expansão do limbo filiar das plantas cultivadas nesse tratamento, haja vista que as plantas cultivadas em recipientes de $1 \mathrm{~L}$ apresentaram menor número de folhas em relação às cultivadas em recipientes de $2 \mathrm{~L}$. Este fato pode estar relacionado ao aumento da área fotossinteticamente ativa em função das condições ótimas de disponibilidade de água e nutrientes, favorecendo a produção de fotoassimilados, já que foi verificado efeito significativo dos tratamentos sob o acúmulo de matéria seca das plantas (Tabela 6). A partir das doses estimadas, houve efeito negativo do biofertilizante, o que pode justificar que as doses estimadas foram suficientes para suprir nutricionalmente os porta-enxertos, inclusive por não terem sido identificados sintomas de deficiência nutricional durante a condução do experimento.

Adicionalmente, são benefícios do uso de estercos animais e biofertilizantes proporcionar melhorias nas propriedades físicas, químicas e biológicas do solo. Respostas positivas da aplicação do biofertilizante sob o ganho de área foliar também foram verificadas por Sá et al. (2013) e Dantas et al. (2014) em mudas de mamoeiro e aceroleira, respectivamente.

As doses de biofertilizante não influenciaram significativamente a razão da área foliar dos porta-enxertos cultivados em recipientes de $1 \mathrm{~L} \mathrm{com}$ Neossolo, obtendo uma razão média de $94,2 \mathrm{~cm}^{2} \mathrm{~g}^{-1}$ (Figura 5). Todavia, as plantas cultivadas em recipientes de $2 \mathrm{~L}$ com Neossolo e as plantas cultivadas com Luvissolo em recipientes de 1 e $2 \mathrm{~L}$ responderam de forma linear e decrescente às doses de biofertilizantes aplicadas, com reduções unitária de 18,$202 ; 8,996$ e $9,5052 \mathrm{~cm}^{2} \mathrm{~g}^{-1}$, respectivamente, para cada aumento de $1 \%$ da dose de biofertilizante aplicada (Figura 5).

De acordo com Ferri (1985), a razão de área foliar é importante para avaliar a dimensão relativa do órgão assimilador utilizado como parâmetro apropriado nas avaliações dos efeitos genotípicos, de manejo, e climáticos das comunidades vegetais, estando relacionada com a produção de fitomassa resultante do processo de fotossíntese. 

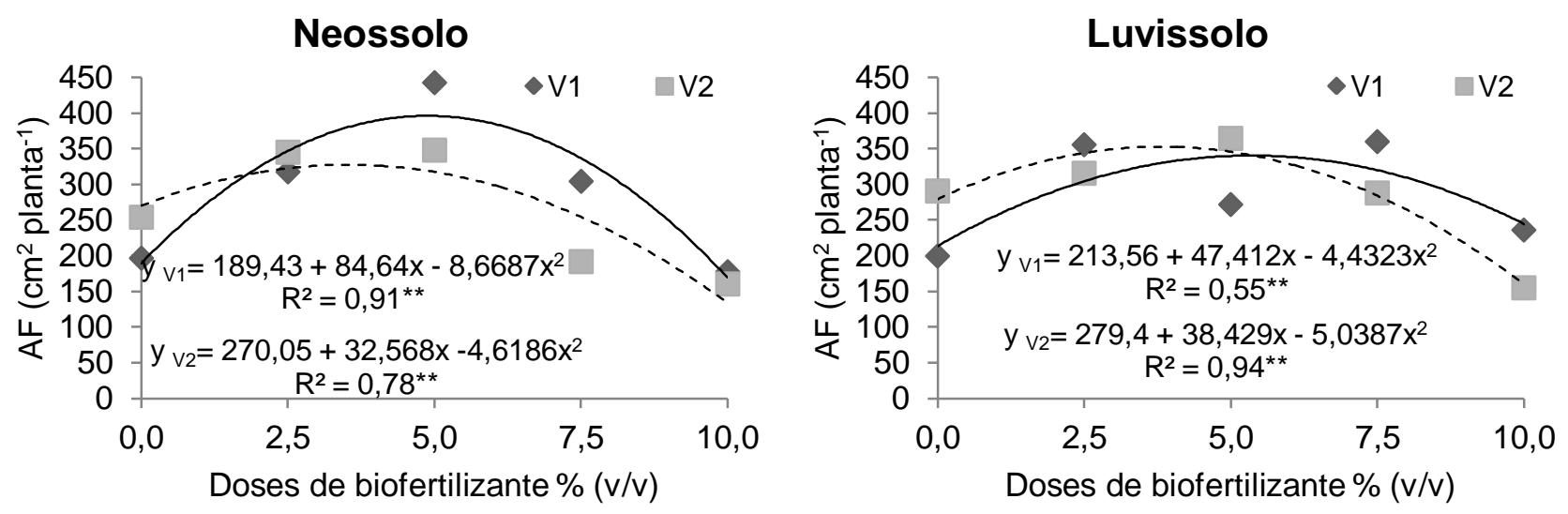

Figura 4 - Área foliar(AF) de porta-enxertos de goiabeira em função de doses de biofertilizante no substrato, volume do vaso $(\mathrm{V} 1=1 \mathrm{~L} ; \mathrm{V} 2=2 \mathrm{~L})$ e tipo do solo usado como substrato. Leaf area $(\mathrm{AF})$ of rootstocks of guava as a function of dose of biofertilizer, volume and type of soil used as substrate.

Pequenos valores da razão de área foliar são indicativos de que os produtos fotoassimilados estão sendo mais bem aproveitados; por outro lado, a taxa de assimilação líquida expressa o aumento do crescimento por unidade de área foliar em função do tempo e estima a fotossíntese líquida e a magnitude do sistema assimilador envolvido no processo produtivo de matéria seca. Implicando que o aumento das doses de biofertilizante está favorecendo a atividade fotossintética dos porta-enxertos como também o acúmulo de biomassa, como pode ser observado na matéria seca da parte aérea, com exceção dos tratamentos com $1 \mathrm{~L}$ de substrato com Neossolo (Figura 8).
Neossolo

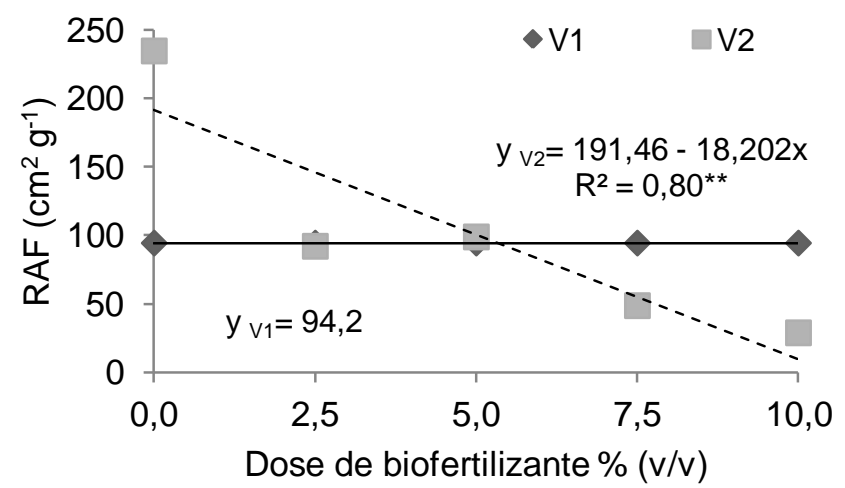

Luvissolo

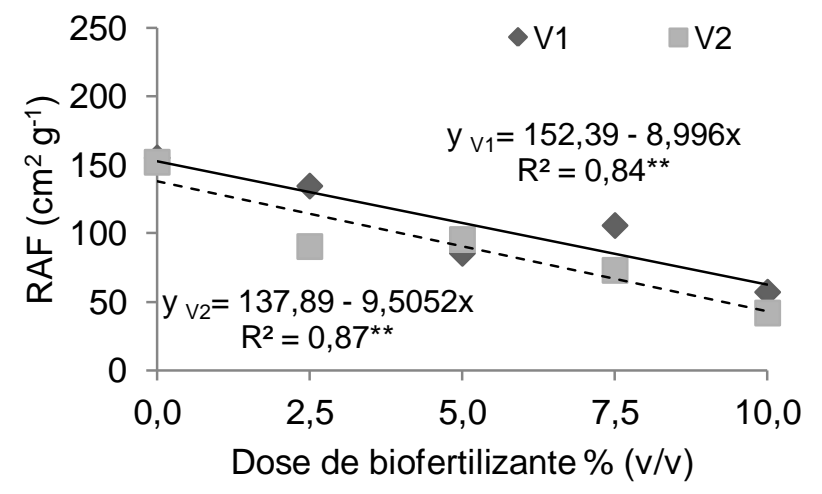

Figura 5 - Razão de área foliar (RAF) de porta-enxertos de goiabeira em função da dose do biofertilizante, volume de substrato $(\mathrm{V} 1=1 \mathrm{~L} ; \mathrm{V} 2=2 \mathrm{~L}$ ) e tipo do solo usado como substrato. Leaf area ratio (RAF) of rootstocks of guava as a function of dose of biofertilizer, volume and type of soil used as substrate.

Análises de variância referentes às variáveis pesos de matéria seca de folhas, caule, de parte aérea, raiz, total e relação raiz parte aérea podem ser observadas na Tabela 6 . Observa-se influência significativa da interação biofertilizante $\mathrm{x}$ solo $\mathrm{x}$ volume para todas as variáveis estudadas. Os coeficientes de variação foram de 13,89\% (MSF), 16,26\% (MSC), $11,52 \%$ (MSPA), $13,69 \%$ (MSR), 9,81\% (MST) e 11,70 0 (RRPA). Segundo Santos et al. (2008) e Pimentel-Gomes (2009), o coeficiente de variação pode ser considerado baixo, quando o $\mathrm{CV}<10 \%$; médio, quando o CV estiver entre 10-20\%; e alto, quando o > $20 \%<$ CV $\leq 30 \%$; e muito alto, quando o CV $>30 \%$. Numa comparação com o coeficiente de variação obtido (CV) no trabalho, observa-se para MST que é considerado baixo, e as demais variáveis estão na faixa de CVs médios, indicando boa precisão na condução do experimento. Tais resultados indicam a importância do estudo dos substratos, volumes e aditivos orgânicos como alternativa para a produção de porta-enxertos, indicando que as condições estudadas influenciaram diretamente na partição de fitomassa dos porta-enxertos.

Os valores de matéria seca de folhas ajustaram-se ao modelo quadrático para os tratamentos com Neossolo, no volume de $1 \mathrm{~L}$, e no Luvissolo, com volume de $2 \mathrm{~L}$ de substrato. Máximos acúmulos de MSF de 2,58 e 2,63 $\mathrm{g}_{\text {planta }}{ }^{-1}$ obtidos com a utilização das doses de biofertilizantes de 4,27 e 7,04\%, respectivamente, ocorrendo respostas negativas com doses superiores (Figura 6). Os tratamentos com substratos compostos por $2 \mathrm{~L}$ de Neossolo e de $1 \mathrm{~L}$ de Luvissolo ajustaram-se ao modelo linear e crescente, sendo a dose mais eficiente a última dose 
analisada, isto é, $10 \%$ do biofertilizante, cuja média respectivamente (Figura 6). de matéria seca de folha foi de 3,57 e 2,87 $\mathrm{g}_{\text {planta }}{ }^{-1}$,

Tabela 6 - Resumo da análise de variância para matéria seca da folha (MSF), matéria seca do caule (MSC), matéria seca da parte aérea (MSPA), matéria seca da raiz (MSR), matéria seca total (MST) e relação raiz parte aérea (RRPA ), em porta-enxerto de goiabeira. Analyses of variance results for leaf dry matter (MSF), stem dry matter (MSC), aerial part dry matter (MSPA), root dry matter (MSR), total dry matter (MST), and root/aerial part relation (RRPA) in guava rootstock.

\begin{tabular}{|c|c|c|c|c|c|c|c|}
\hline \multirow{2}{*}{$\begin{array}{l}\text { Fonte de } \\
\text { Variação }\end{array}$} & \multicolumn{7}{|c|}{ Quadrado Médio } \\
\hline & $\mathrm{GL}$ & MSF & MSC & MSPA & MSR & MST & RRPA \\
\hline Repetição & 2 & $0,04^{\mathrm{ns}}$ & $0,01^{\mathrm{ns}}$ & $0,01^{\mathrm{ns}}$ & $0,07^{\mathrm{ns}}$ & $0,10^{\mathrm{ns}}$ & $0,00^{\mathrm{ns}}$ \\
\hline Biofertilizantes (B) & 4 & $3,38^{* *}$ & $1,41^{\star *}$ & $8,97^{\star *}$ & $3,87^{\star *}$ & $24,50^{* *}$ & $0,00^{\mathrm{ns}}$ \\
\hline Tipos de Solos (S) & 1 & $0,00^{\mathrm{ns}}$ & $0,34^{* *}$ & $0,36^{\mathrm{ns}}$ & $0,03^{\text {ns }}$ & $0,60^{\mathrm{ns}}$ & $0,00^{\mathrm{ns}}$ \\
\hline Volumes (V) & 1 & $0,79^{\star \star}$ & $0,95^{\star}$ & $3,48^{\star *}$ & $8,62^{* *}$ & $23,06^{\star *}$ & $0,04^{* *}$ \\
\hline Interação B*S & 4 & $0,23^{* *}$ & $0,06^{\mathrm{ns}}$ & $0,45^{*}$ & $0,88^{* *}$ & $2,57^{\star *}$ & $0,00^{\mathrm{ns}}$ \\
\hline Interação B*V & 4 & $1,22^{*}$ & $0,24^{\star \star}$ & $2,40^{\star *}$ & $0,94^{* *}$ & $5,64^{\star \star}$ & $0,00^{*}$ \\
\hline Interação S*V & 1 & $0,00^{\mathrm{ns}}$ & $0,06^{\mathrm{ns}}$ & $0,02^{\mathrm{ns}}$ & $2,54^{\star *}$ & $2,05^{\star \star}$ & $0,03^{* *}$ \\
\hline Interação $B^{*} S^{*} V$ & 4 & $2,55^{\star \star}$ & $0,42^{\star *}$ & $4,96^{\star \star}$ & $1,04^{* *}$ & $9,40^{\star \star}$ & $0,00^{\star}$ \\
\hline Resíduo & 38 & 0,08 & 0,03 & 0,14 & 0,08 & 0,27 & 0,00 \\
\hline CV (\%) & & 13,89 & 16,26 & 11,52 & 13,69 & 9,81 & 11,70 \\
\hline
\end{tabular}

GL - Grau de Liberdade; CV - Coeficiente de Variação; ns= Não Significativo; ${ }^{* *}=$ Significativo ao nível de $1 \%$ de probabilidade; ${ }^{*}=$ Significativo ao nível de $5 \%$ de probabilidade.

Acredita-se que o aumento da dose de biofertilizante nos tratamentos de $2 \mathrm{~L}$ com Neossolo favoreceu maior disponibilidade de nutrientes, em função de esse solo apresentar fertilidade inferior ao Luvissolo e que o maior volume pode ter proporcionando efeito de diluição da fertilidade do solo e, com isso, maior acúmulo de fitomassa nas plantas. No Luvissolo, é possível que o aumento das doses de matéria orgânica estimulou a maior permeabilidade de solo e, com isso, sua maior aeração, favorecendo o desenvolvimento e a assimilação de carbono nas plantas.

As plantas responderam positivamente, até certo nível, à adição de biofertilizante bovino no

\section{Neossolo}

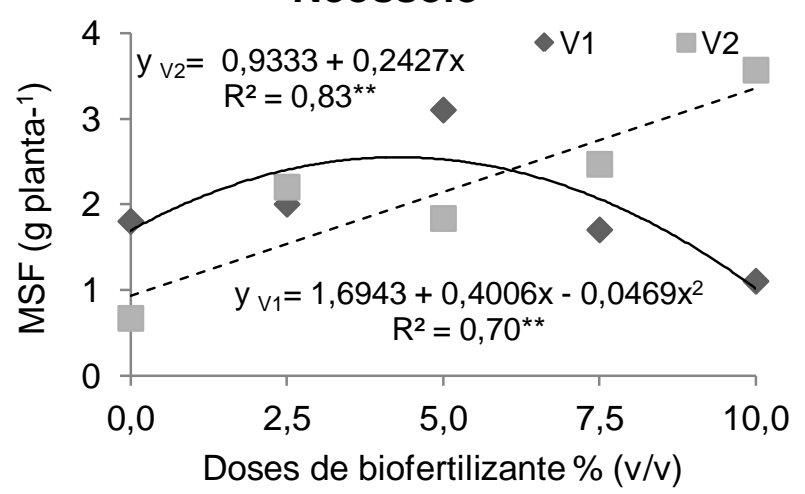

substrato, independentemente do solo utilizado, corroborando Nascimento (2010), ao afirmar que o biofertilizante derivado dos biodigestores anaeróbios é um efluente líquido que, após a fermentação das bactérias no interior do equipamento, pode alterar beneficamente as propriedades físicas, químicas e biológicas do solo. Pode, ainda, melhorar a capacidade de retenção de água, por ser uma matéria orgânica, além de possuir os elementos essenciais ao desenvolvimento das plantas, estimulando com isso maior crescimento e acúmulo de fitomassa pelas plantas.

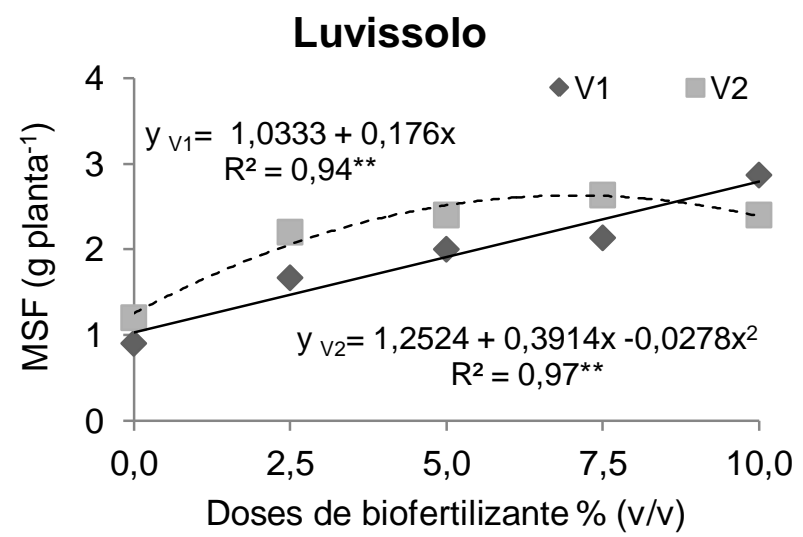

Figura 6 - Matéria seca da folha (MSF) de porta-enxertos de goiabeira em função da dose de biofertilizante, volume de substrato $(\mathrm{V} 1=1 \mathrm{~L} ; \mathrm{V} 2=2 \mathrm{~L})$ e tipo do solo usado como substrato. Guava rootstock leaf dry matter (MSF) as influenced by biofertilizer dose, soil volume, and soil type. 
Para o matéria seca de caule, as doses de biofertilizante bovino máximas estimadas de 4,97 e 8,60 proporcionaram os melhores resultados, com 1,51 e $1,89 \mathrm{~g}$ nos volumes de 1 e $2 \mathrm{~L}$ de substrato com Neossolo, respectivamente. Observa-se ainda que esses resultados foram superiores aos obtidos no Luvissolo, que obtiveram 1,33 e 1,49 g, nas doses de 8,21 e $6,30 \%$ do volume do substrato nos recipientes de 1 e $2 \mathrm{~L}$, respectivamente (Figura 7), averiguando-se com isso que o Neossolo se apresenta como mais promissor para a produção de mudas da goiabeira, possivelmente em função de sua granulometria (Tabela 1). Segundo Santos (2001), a aplicação regular de biofertilizantes resulta em grande desenvolvimento vegetativo com aumento do número e tamanho das células vegetais e o espessamento das paredes das células da camada

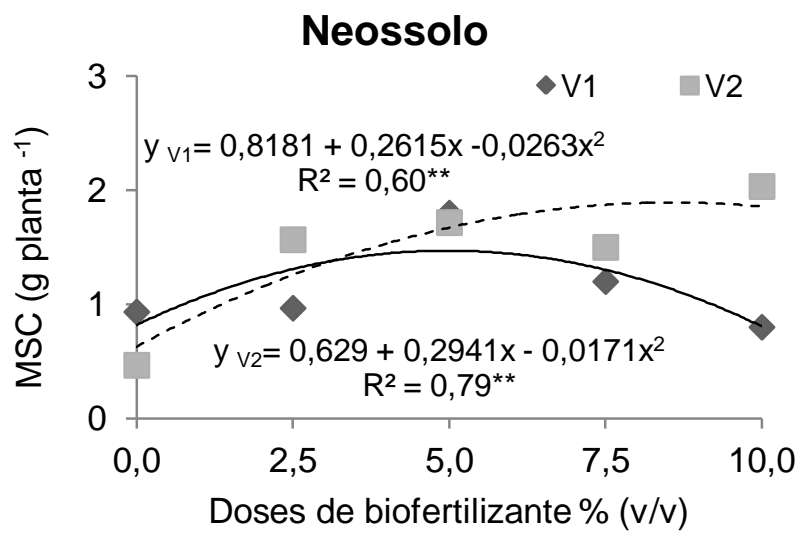

da epiderme vegetal e, consequentemente, da área foliar, produzindo maior fitomassa seca. No entanto, quando em excesso, pode provocar efeitos deletérios às plantas, a exemplo da toxicidade, como verificado neste trabalho, pelas reduções observadas na fitomassa das plantas de goiabeira.

Quanto à matéria seca da parte aérea, observou-se resposta linear e crescente nos portaenxertos produzidos no Neossolo, em recipientes de $2 \mathrm{~L}$, e no Luvissolo, em recipientes de $1 \mathrm{~L}$. No entanto, para os porta-enxertos produzidos em recipientes de $1 \mathrm{~L}$ com Neossolo e de $2 \mathrm{~L}$ com Luvissolo, verificaram-se respostas quadráticas em função das doses de biofertilizantes, constatando decréscimo na produção de matéria seca do caule quando adubados com biofertilizante a 4,52 e $6,75 \%$ do volume do substrato, respectivamente (Figura 8).

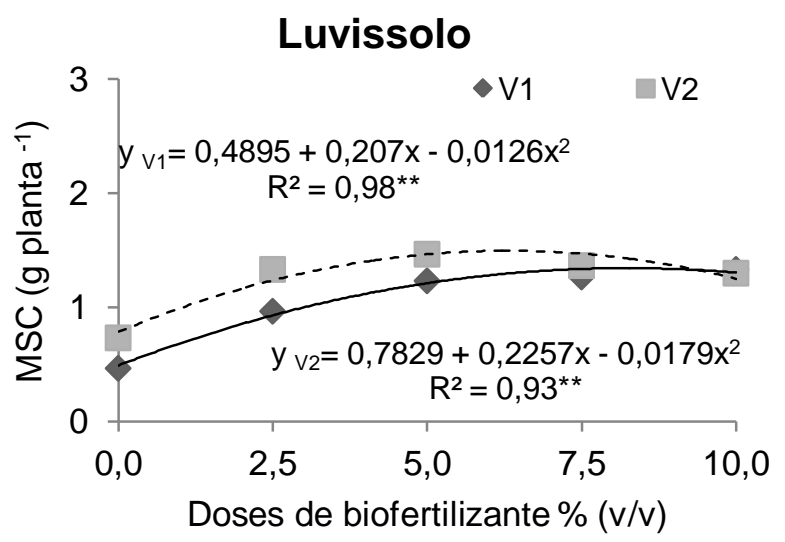

Figura 7 - Matéria seca do caule (MSC) de porta-enxertos de goiabeira em função da dose de biofertilizante, volume de substrato (V1 = $1 \mathrm{~L} ; \mathrm{V} 2=2 \mathrm{~L})$ e tipo do solo usado como substrato. Guava rootstock stem dry matter (MSC) as influenced by biofertilizer dose, soil volume, and soil type.

Acredita-se que no Neossolo, por apresentar menor fertilidade em relação ao Luvissolo (Tabela 1), as respostas quadráticas observadas em recipientes de $2 \mathrm{~L}$ estão relacionadas à maior capacidade de diluição das doses de biofertilizante em função do volume do solo. No entanto, quando estas doses são aplicadas em recipientes de $1 \mathrm{~L}$, o efeito de diluição e a retenção dos nutrientes pelo solo são menores, ocasionando com isso superdosagens de nutrientes fornecidos aos porta-enxertos de goiabeira, resultando com isso em respostas quadráticas.

Todavia, devido à maior fertilidade do Luvissolo em relação ao Neossolo (Tabela 1), quando estes são acondicionados em recipientes de $2 \mathrm{~L}$, apesar de ter a composição na mesma proporção utilizada nos recipientes de $1 \mathrm{~L}$, acabam comportando quantidades maiores de solo e esterco bovino em função de seu volume. Com isso, aumenta-se a concentração de nutrientes mesmo sem adição do biofertilizante, além de que a quantidade de biofertilizante é maior nos recipientes de $2 \mathrm{~L}$ em função do maior volume de solo, o que, provavelmente, proporciona efeito toxico nos porta-enxertos de goiabeira, verificado pelo comportamento quadrático. Esse fato não foi verificado nos recipientes de $1 \mathrm{~L}$, possivelmente em função das menores concentração de esterco e solo, como também das menores quantidades de biofertilizante em função do volume do recipiente.

Paulus et al. (2000) relatam que o biofertilizante líquido, ao ser aplicado, deve estar bem fermentado e, preferencialmente, ser aplicado sob temperaturas amenas, levando-se em consideração a matéria orgânica do solo, a fertilidade e a estrutura do mesmo, justificando o efeito negativo do biofertilizante acima das doses estimadas.

Verificou-se que as doses influenciaram significativamente sobre a matéria seca de raiz ( $\mathrm{g}$ planta $^{-1}$ ), independentemente do tipo de solo e do volume do substrato utilizado (Figura 9). Na produção de porta-enxertos em substratos com Neossolo, verificou-se comportamento quadrático em função das doses de biofertilizante, sendo estipulado acúmulo máximo de matéria seca nas doses de 4,69 e $7,40 \%$ do volume do substrato, correspondentes aos acúmulos de 2,63 e 2,90 g para os recipientes de 1 e $2 \mathrm{~L}$, respectivamente (Figura 9). 

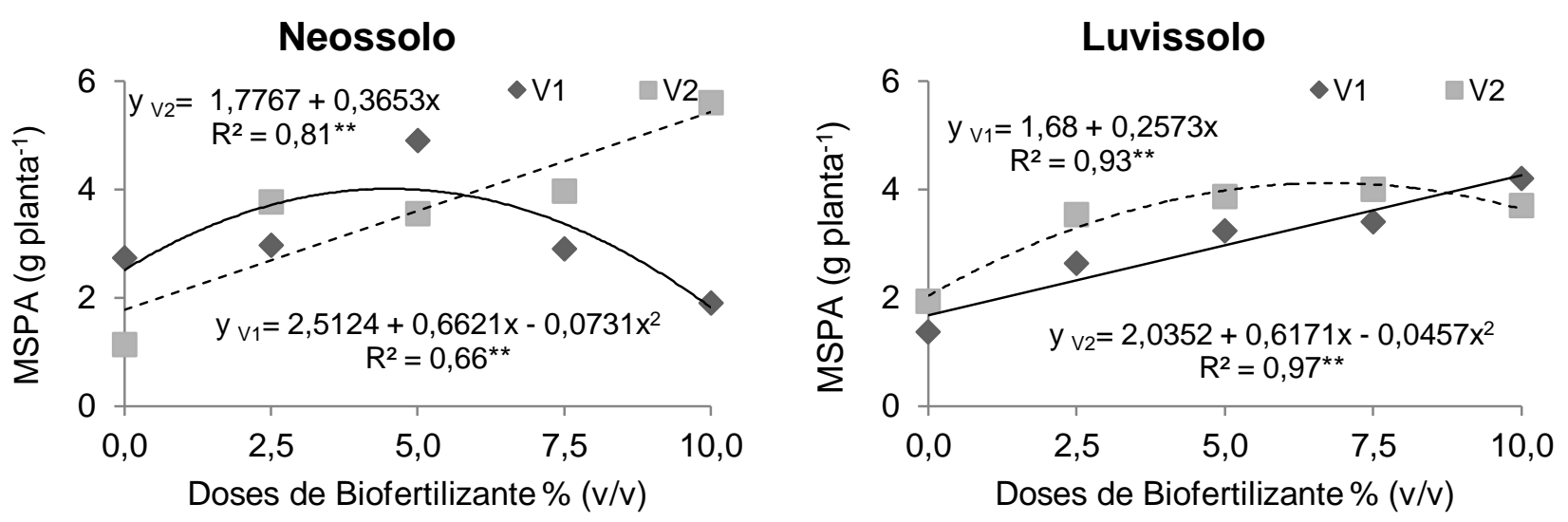

Figura 8 - Matéria da parte aérea (MSPA) de porta-enxertos de goiabeira em função da dose de biofertilizante, volume de substrato (V1 = $1 \mathrm{~L} ; \mathrm{V} 2=2 \mathrm{~L}$ ) e tipo do solo usado como substrato. Guava rootstock aerial part dry matter (MSPA) as influenced by biofertilizer dose, soil volume, and soil type.

Nos substratos contendo Luvissolo, constatou-se resposta linear e crescente dos portaenxertos produzidos em recipientes de $1 \mathrm{~L}$, respondendo de maneira semelhantes ao acúmulo de matéria seca da parte aérea, o que pode estar relacionado ao equilíbrio de desenvolvimento dessas plantas, assim como pode ser observado na RRPA (Figuras 8 e 11). Ainda no Neossolo, verificou-se resposta quadrática das mudas produzidas em recipientes de $2 \mathrm{~L}$ com pico máximo de acúmulo de matéria seca das raízes $(3,27 \mathrm{~g})$, na dose de $7,70 \%$ do volume do substrato (Figura 9). Provavelmente, as doses estimadas de biofertilizantes e o esterco bovino contido no substrato melhoraram os atributos biológicos, físicos e químicos do solo, incrementando aumento do peso seco das raízes. No entanto, aplicações acima das doses de máxima eficiência física podem ter causado efeitos negativos às plantas.

Os resultados obtidos na presente pesquisa corroboram Viana et al. (2003), que estudaram o cultivo da cenoura com diferentes tratamentos (adubação verde, composto orgânico e biofertilizante), obtendo melhor resultado com a aplicação do biofertilizante. Os referidos autores observaram que utilizando via solo, ocorreu maior produção das raízes.

A matéria seca total (g planta ${ }^{-1}$ ) segue em função do acúmulo de matéria seca da parte aérea e da raiz, a qual, assim com ela, foi influenciada diretamente pela interação biofertilizante, solos e volumes (Figura 10). Assim como verificado na matéria seca da parte aérea, observou-se resposta linear e crescente nos porta-enxertos produzidos no Neossolo em recipientes de $2 \mathrm{~L}$ e no Luvissolo em recipientes de $1 \mathrm{~L}$. No entanto, para os portaenxertos produzidos em recipientes de $1 \mathrm{~L}$ com Neossolo e de 2 L com Luvissolo, verificaram-se respostas quadráticas em função das doses de biofertilizantes, denotando que esta exerce maior influência sobre a matéria seca dos porta-enxertos de goiabeira em relação à matéria seca da raiz
(Figuras 8, 9 e 10). Acredita-se, com isso, que as repostas do acúmulo de fitomassa das plantas de goiabeira partiram principalmente em função da fertilidade e das características granulométricas dos solos estudados, sendo o Neossolo o mais promissor para produção de porta-enxertos de goiabeira por promover os maiores acúmulos de matéria seca, independentemente do volume do substrato. Acredita-se ainda que as características granulométricas foram mais marcantes que a própria fertilidade do solo, em função do fornecimento de nutrientes via biofertilizante e esterco bovino. Nascimento et al. (2009) também observaram respostas positivas da adubação orgânica sobre o acúmulo de fitomassa em mudas de goiabeira. Os autores obtiveram os maiores acúmulos de fitomassa nas mudas produzidas em substratos compostos por solo $(60 \%)$, areia (10\%) e esterco bovino (30\%), atingindo $48,60 \mathrm{~g}$ planta $^{-1} \mathrm{em}$ mudas de goiabeira Paluma propagadas por estaquia.

Quanto à relação raiz parte aérea, não foi verificado ajuste significativo das doses de biofertilizante para as plantas cultivadas em recipientes de $1 \mathrm{~L}$, independentemente dos tipos de solo, obtendo médias de 0,38 e $0,34 \mathrm{~g} \mathrm{~g}^{-1}$ para os porta-enxertos cultivados em Neossolo e Luvissolo, respectivamente, indicando equilíbrio de crescimento entre o sistema radicular e a parte aéreas dos porta-enxertos (Figura 11). Para o tratamento com Neossolo em recipientes de $2 \mathrm{~L}$, foi observado resposta linear decrescente em função das doses de biofertilizante, inferindo em maior acúmulo de matéria seca na parte aérea em relação ao sistema radicular dos porta-enxertos.

Possivelmente, a redução do sistema radicular, observada nas maiores doses de biofertilizante aplicadas ao solo, está relacionada ao mecanismo de adaptação da planta, reduzindo a superfície de contato com o solo por meio da redução do sistema radicular e, com isso, limitando a absorção de nutrientes, evitando assim possíveis efeitos de toxicidade. 

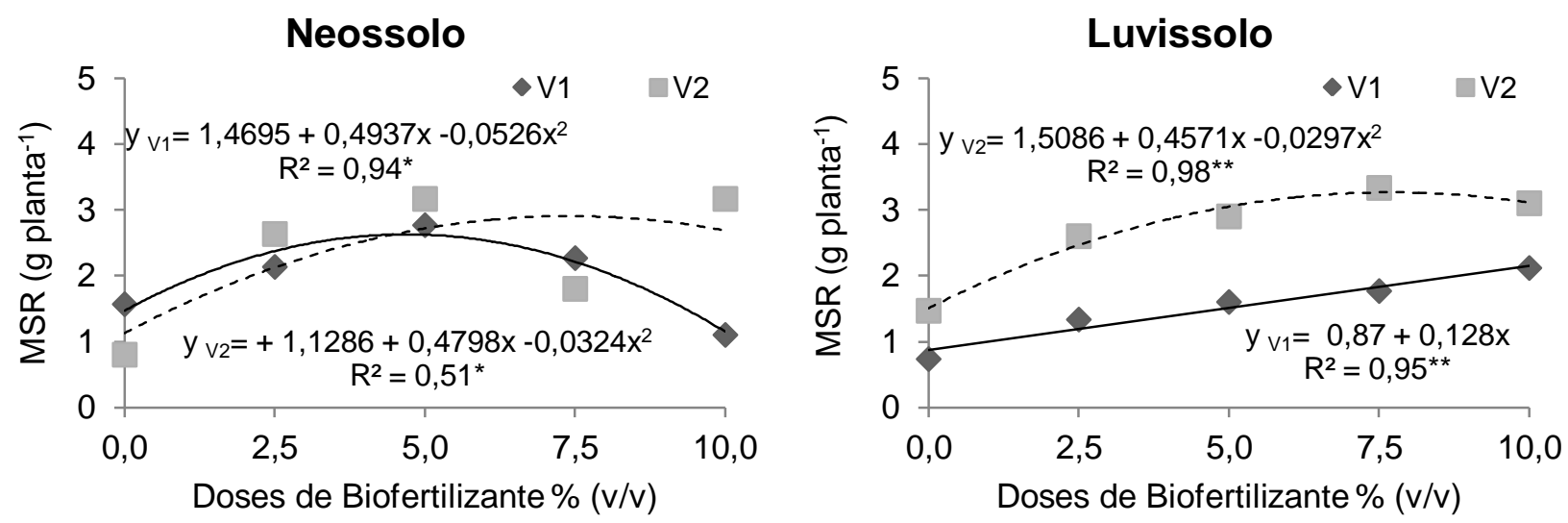

Figura 9 - Matéria seca de raiz (MSR) de porta-enxertos de goiabeira em função da dose de biofertilizante, volume do substrato (V1 = $1 \mathrm{~L} ; \mathrm{V} 2=2 \mathrm{~L}$ ) e tipo do solo usado como substrato. Guava rootstock root dry matter (MSR) as influenced by biofertilizer dose, soil volume, and soil type.
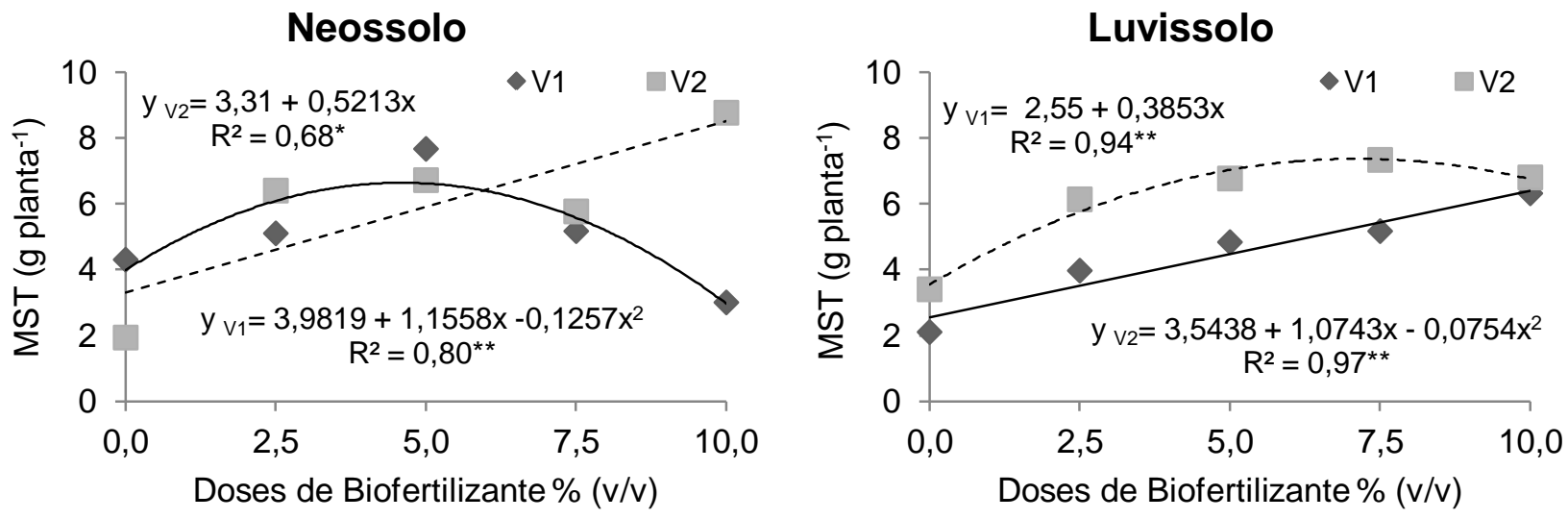

Figura 10 - Matéria seca total (MST) de porta-enxertos de goiabeira em função da dose de biofertilizante, volume do substrato (V1 = $1 \mathrm{~L} ; \mathrm{V} 2=2 \mathrm{~L}$ ) e tipo do solo usado como substrato. Guava rootstock total dry matter (MST) as influenced by biofertilizer dose, soil volume, and soil type.
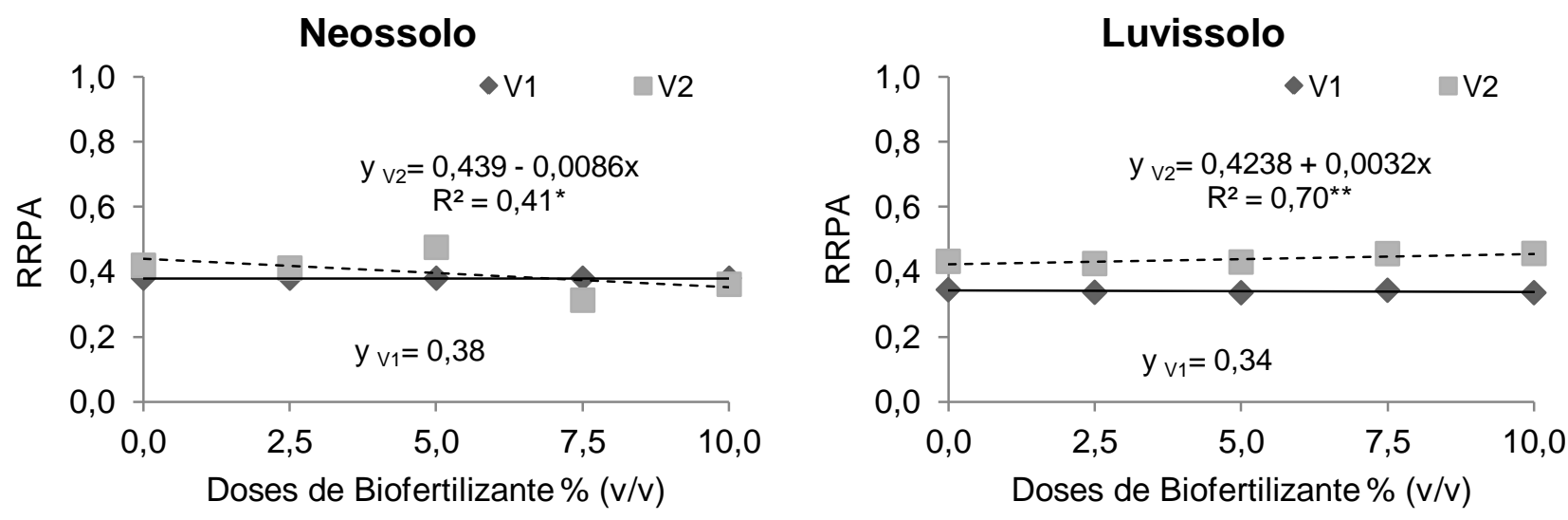

Figura 11 - Relação Raiz Parte Aérea (RRPA) de porta-enxertos de goiabeira em função da dose de biofertilizante, volume de substrato $(\mathrm{V} 1=1 \mathrm{~L} ; \mathrm{V} 2=2 \mathrm{~L})$ e tipo do solo usado como substrato. Guava rootstock root/aerial part (RRPA) relation as influenced by biofertilizer dose, volume and type of soil

Resposta contrária foi observada nos portaenxertos cultivados no Luvissolo em recipientes de 2 litros, que responderam de maneira linear crescente ao aumento da dose de biofertilizante, indicando maior desenvolvimento do sistema radicular, possivelmente em função de aumentar a exploração de água e de nutrientes no solo (Figura 11). A relação raiz parte aérea é uma característica para avaliar a qualidade de porta-enxerto, sendo que quanto maior a relação entre a massa seca do sistema radicular e a parte aérea, 
melhor a qualidade da muda (Samôr et al., 2002). Entretanto, os mesmos autores recomendam não analisar isoladamente esta variável. Como se observa neste trabalho, os melhores resultados foram obtidos pelos porta-enxertos produzidos em substrato com Neossolo, podendo-se dizer que essa variável não reflete bem a qualidade das mudas de goiabeira.

\section{Conclusões}

O maior crescimento e o acúmulo de matéria seca foram obtidos pelos porta-enxertos cultivados em recipientes com capacidade para 2 litros de substratos.

De maneira geral, doses de biofertilizante próximas a $5 \%$ do volume do substrato proporcionaram o maior desenvolvimento dos porta-enxertos de goiabeira.

Os tipos de solo afetaram o crescimento dos porta-enxertos, sendo o Neossolo o mais promissor para produção de porta-enxertos de goiabeira.

\section{Referências}

Carneiro JGA (1983) Variações na metodologia de produção de porta-enxertos florestais afetam os parâmetros morfofisiológicos que indicam a sua qualidade. FUPEF: Curitiba, n.12, p.1-40.

Cavalcante LF, Vieira MS, Santos AF, Oliveira WM, Nascimento JAM (2010) Água salina e esterco bovino líquido na formação de porta-enxerto de goiabeira cultivar Paluma. Revista Brasileira de Fruticultura, 32(1): 251-261. doi: 10.1590/S010029452010005000037

Dantas KA, Figueiredo TC, Mesquita EF, Sá FVS, Ferreira NM (2014) Substratos e doses de biofertilizante bovino na produção de porta-enxerto de aceroleira. Revista Verde de Agroecologia e Desenvolvimento Sustentavel, 9(1): 157-162.

EMBRAPA (2006) Sistema Brasileiro de Classificação de Solos. 2. ed. Rio de Janeiro, 212p.

Ferreira DF (2011) Sisvar: a computer statistical analysis system. Ciência e Agrotecnologia, 35(6): 1.039-1.042.

Ferri, MG (1985) Fisiologia vegetal 1. 2ed. São Paulo: EPU, 362p.

Gurgel MT, Gheyi HR, Fernandes PD, Santos FJS, Nobre RG (2007) Crescimento inicial de portaenxertos de goiabeira irrigados com águas salinas. Revista Caatinga, 20(2): 24-31.

IBGE - Instituo Brasileiro de Geografia e Estatística (2012). Sidra - Produção Agrícola Municipal, 2012. Disponível em: <http:// www.sidra.ibge.gov.br> (Acesso em 25 Janeiro 2014).

Malavolta E (1989) ABC da adubação. São Paulo:
Agronômica Ceres, 292p.

Nascimento RC (2010) O uso do biofertilizante em solos agrícolas do cerrado da região do alto Paranaíba (MG). Boletim Goiano Geografia, 30(2): 55-66.

Nascimento RS, Pereira WE, Silva Neto JJ, Lucena EHL, Oliveira CJ, Perazzo AF (2009) Crescimento e composição mineral de porta-enxerto de goiabeira 'Paluma' em substratos orgânicos. Simpósio Brasileiro da Cultura da Goiaba, 3. Anais.... Jaboticabal: SBF, 1-4p. CD - ROM.

Pereira FM, Carvalho C, Nachtigal JC (2003) Século XXI: nova cultivar de goiabeira de dupla finalidade. Revista Brasileira de Fruticultura, 25(3): 498-500.

Pimentel-Gomes F (2009) Curso de estatística experimental. Piracicaba: FEALQ, 541p.

Paulus G, Muller AM, Barcellos LAR (2000) Agroecologia aplicada: práticas e métodos para uma agricultura de base ecológica. Porto Alegre: EMATER/RS, 86p.

Rozane, DE, Couto FAA (2003) Cultura da goiabeira: tecnologia e mercado. Viçosa: UFV, 402p.

Ruggiero C (2009) O potencial da fruticultura para o século XXI. In: Natale W, Rozane DE, Souza HA, Amorim DA (eds) Cultura da goiaba do plantio à comercialização, p. 13-27.

Sá FVS, Mesquita, EF, Bertino AMP, Silva GA, Costa JD (2013) Biofertilizantes na produção hidropônica de porta-enxerto de mamoeiro. Revista Verde de Agroecologia e Desenvolvimento Sustentável, 8(3): 109-116.

Samôr OJM, Carneiro JGA, Barroso DG, Leles PSS (2002) Qualidade de porta-enxerto de na gico e sesbânia, produzidas em diferentes recipientes e substratos. Revista Árvore, 2: 209-215.

Santos GD (2001) Avaliação do maracujazeiroamarelo sob biofertilizantes aplicados ao solo na forma líquida. CCA/UFPB (Dissertação de Mestrado em Manejo de Solo e Água).

Santos HG, Jacomine PKT, Anjos LHC, Oliveira VA, Oliveira JB, Coelho MR, Lumbretas JF, Cunha TJF (2006) Sistema brasileiro de classificação de solos. Rio de Janeiro: Embrapa Solos, 306p.

Santos JW, Almeida FAC, Beltrão NEM, Cavalcanti FB (2008) Estatística Experimental aplicada. 2 ed. Campina Grande: EMBRAPA ALGODÃO:UFCG, $461 \mathrm{p}$.

Trindade AV, Faria NG, Almeida FP (2000) Uso de esterco no desenvolvimento de mudas de mamoeiro colonizadas com fungos micorrízicos. Pesquisa Agropecuária Brasileira, 35(7): 1389-1394. 
Vairo ACS, Akiba F (1996) Biofertilizante líquido: uso correto na Agricultura alternativa. Imprensa Universitária. Seropédica, 35p.

Viana JV, Bruno RLA, Silva VF, Santos GP, Araújo Filho JOT (2003) Produção de cenoura (DaucuscarotaL.) sob diferentes fontes de adubação. In: CONGRESSO BRASILEIRO DE OLERICULTURA, 43, Anais.... 1-4p.CD-ROM.
Zietemann C, Roberto SR (2007) Produção de mudas de goiabeira (Psidiumguajava L.) em diferentes substratos. Revista Brasileira de Fruticultura, 29(1): 137-142. 